IP Periodica Polytechnica Civil Engineering

\author{
59(2), pp. 165 1722015 \\ DOI: $10.3311 /$ PPci.7658 \\ Creative Commons Attribution (1) \\ RESEARCH ARTICLE
}

\section{Terrain Model Resolution Effect on Sight Distance on Roads}

\author{
Maria Castro, Alvaro García-Espona, Luis Iglesias
}

Received 10-08-2014, revised 24-11-2014, accepted 17-02-2015

\begin{abstract}
Available sight distance is a key factor on road design. This research is focused on the effect of Digital Terrain Model (DTM) resolution on available sight distance. In addition, the effect of distance between calculation points along the vehicle path is also considered. The available sight distance is calculated using a Geographic Information System (GIS). Three high resolution DTMs, based on airborne LiDAR (Light Detection and Ranging), are used. Vehicle path is collected by a Global Navigation Satellite System (GNSS) mounted in a vehicle travelling along the road. Twelve combinations of DTM resolution and distance between calculation points along the vehicle path are studied. Results are statistically analysed and each case study is compared to a reference case which is considered close to reality. The analysis made shows that DTM resolution has a larger effect on the quality of the results than distance between calculation points. Practical issues are discussed.
\end{abstract}

\section{Keywords}

Available sight distance - Geographic Information System (GIS) · Digital Terrain Model (DTM) · Global Navigation Satellite System (GNSS) · Light Detection and Ranging (LiDAR) · traffic safety

\section{Maria Castro}

Associate Professor, Dept. Transportes, E.T.S.I.C.C.P., Universidad Politécnica de Madrid, Prof. Aranguren s/n, 28040-Madrid, Spain e-mail: maria.castro@upm.es

\section{Alvaro García-Espona}

Research Assistant, Dept. Transportes, E.T.S.I.C.C.P., Universidad Politécnica de Madrid, Prof. Aranguren s/n, 28040-Madrid, Spain

e-mail: al.garcia-espona@alumnos.upm.es

\section{Luis Iglesias}

Associate Professor Dept. Explotación de Recursos Minerales y Obras Subterráneas. E.T.S.I.M., Universidad Politécnica de Madrid, Ríos Rosas, 21, 28003 Madrid, Spain

e-mail: luis.iglesias@upm.es

\section{Introduction}

Traffic safety is a key factor on the design, construction and management of roads. Traffic accidents entail significant social and economic losses, and must be contained. An essential parameter of traffic safety is the distance that the driver can see along the vehicle path. That is of major importance when hazardous manoeuvres must be done, such as an emergency stopping or an overtaking. Several studies have shown the existence of a direct link between accident rate and available sight distance [16, 17].

On operating roads, deficient visibility can be produced by a mistake during the design phase or by changes on the initial visibility conditions over time, due to natural or human actions. The majority of the studies are focused on the visibility of new roads, thus it is important to perform a study on the visibility of operating roads. Available sight distance studies have been usually based on the use of simplified mathematical models or specific software for road design. Nowadays, Geographic Information System (GIS) can be used for studies on designing new roads or already built roads. In addition, GIS allows the integration of other factors related to traffic safety (e.g. crashes).

Regardless of the method used to calculate available sight distance, the terrain model accuracy (of the road and its surrounding) is, in principle, a factor which could influence final results. The distance between calculation points along the vehicle path is linked to Digital Terrain Model (DTM) resolution and could also influence the results. The aim of this study is to analyze the influence of DTM resolution and distance between calculation points along the vehicle path on the results of available sight distance.

The first section of document summarizes the basic concepts. Materials and methodology are presented below. Twelve combinations of DTM resolution and distance between calculation points along the vehicle path are studied. Finally, the analysis of these combinations is discussed.

\section{Literature review}

Available sight distance (ASD) is defined as the distance that the driver can see along the vehicle path on road (arc $\mathrm{AD}$ in 
Fig. 11 and distance AD in Fig. 13). This distance allows the driver to notice the information in real time, adopting the driving to the circumstances of the road and its surrounding. Note that ASD and line of sight (LOS) are related, but different concepts.

Geometric design standards include mathematical models for calculating available sight distance [1, 12, 15]. They are twodimensional (2D) models. That is, horizontal and vertical layout are separately analyzed (Fig. 1). In recent years, there is an increasing number of researchers suggesting three-dimensional (3D) tools to calculate available sight distance [3, 7, 8, 10, 20]. One way of making this 3D calculation is using a GIS.

The main advantage of the GIS is that allows the integration of the sight analysis with other factors related to traffic safety, as consistency analysis of road design as well as with the accident rate under the same computer platform [11,18]. To make available sight distance calculation using GIS, Castro et al. [4] have developed a software, that allows to determine the visible area for a driver in a road section. This software runs on top ArcGIS, determining which one is the first point not visible along the vehicle path. Sight distance is measured over the vehicle path between the point from which is made the calculation to point immediately previous to the first that is not visible.

To do sight distance calculation with GIS, the following information is needed: driver height, target height, vehicle path and a model of roadway and roadsides (digital terrain model). Vehicle path along the road can be estimated assuming that the vehicle is at a fixed distance from shoulder or road center line. The true path of the vehicle obtained through a Global Navigation Satellite System (GNSS) device can also be considered.

To calculate available sight distance using GIS, there are two possibilities:

1 Calculate first the viewshed of the point where the driver is (i.e. the area which is visible from the point where the driver is). After, calculate the road section included in this viewshed (determining the point D in Fig. 2a) and then calculate the length of arc $\mathrm{AD}$. This procedure was implemented by Castro et al. [5] in Arc-GIS using ModelBuilder.

2 Calculate LOS profiles between path points and determine the most distant point of the path seen by the driver (Fig. 2p). Based on this procedure, which is computationally more efficient, Castro et al. [4] have developed an Add-In for Arc-GIS (used in this research as described in section 3).

Some authors have been studied the effects of DTM resolution on the viewsheds. Fisher [6] studied the effects of DEM resolution in database generalization on the viewshed. Ruiz [14] analyzed the error in viewsheds from United States Geological Survey digital elevation models. Kidner et al. [9] and Berry and Kidner [2] demonstrated the sensitivity of many LOS profiles to very small elevation errors. Murgoitio et al. [13] highlights the importance of the accuracy of the models for studies of visibility. However, there is no specific study about effect of terrain qual- ity representation (road and its surrounding) on sight distance of roads.

Another factor that can influence on available sight calculation is the distance between calculation points (arcs $\mathrm{AB}, \mathrm{BC}$, and $\mathrm{CD}$ in Fig. 2p). A big distance between points will decrease accuracy and validity of results. A little distance will increase the number of calculations and, therefore, the process cost. According to Kuhn and Jha [10] $20 \mathrm{~m}$ is a frequent value used in Germany. However, there is no specific study about impact of distance between calculation points on sight distance of roads.

\section{Materials and methods}

This study has been performed on a two-lane rural highway of $15 \mathrm{~km}$ in Madrid (Spain). This highway has zones with different terrain types (level and rolling) and a geometric design with several sight-hidden dips. Its horizontal alignment has 55 curves, with radii between 30 and $850 \mathrm{~m}$, and 55 tangents, with an average length of $200 \mathrm{~m}$ and a maximum length around $900 \mathrm{~m}$. Maximum grade is $6 \%$ and it has 28 crest and 35 sag vertical curves. For these reasons, it has been chosen.

A tool has been developed in .NET for calculation and analysis of the ASD based on the path of the vehicle and a DTM. This tool has been integrated into ArcGIS Desktop as an add-in and can be added to any toolbar as a button. The sight distance is calculated by determining the first point on the path, which is not visible from the location of the vehicle. The algorithm uses the "GetLineOfSight" extension of ArcMap "3D Analyst". This software has been chosen for its calculation capability and because it allows the integration in an easy way of additional information, being supported by a GIS, (e.g. crashes) that could be useful in more comprehensive studies [4].

For the study of DTM resolution influence it was used three resolutions: $5 \mathrm{~m}$ (DTM05), $2 \mathrm{~m}$ (DTM02) and $1 \mathrm{~m}$ (DTM01). DTM02 and DTM05 have been obtained from model DTM01 through a generalization process. For that, in first $2 \times 2 \mathrm{~m}$ block for DTM02 or $5 \times 5 \mathrm{~m}$ block for DTM05, one of the points has been selected, choosing in the others blocks those points that were founded in the same relative position inside the block. DTM01 model has been obtained with a LiDAR flight. A buffer with $1000 \mathrm{~m}$ width $(50 \mathrm{~m}$ on either side of the center of the road) and circa $15 \mathrm{~km}$ in length. Therefore, DTM01 was circa 14.9 million points, DTM02 3.7 million, and DTM05, 0.6 million.

In all cases, according to Spanish Design Standard [12], driver height is $1.1 \mathrm{~m}$ and target height is $0.2 \mathrm{~m}$. Also, sight distances larger than $1000 \mathrm{~m}$ are not considered. Vehicle path is based on data collected by a GNSS mounted in a vehicle travelling along the highway. The GNSS receiver used was a Topcon GR-3 multi-frequency receiver that can receive and process multiple signal types including GPS L2C, GPS L5, GLONASS C/A L2 and GALILEO and provides access to 72-channel tracking [19]. The receiver antenna was mounted on the top of the vehicle, threaded into a robust magnetic base. Data were collected in Real Time Kinematic (RTK) mode and differentially corrected 


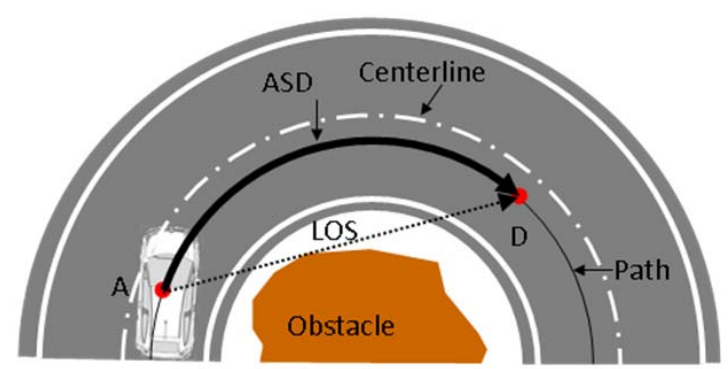

a) Plan view

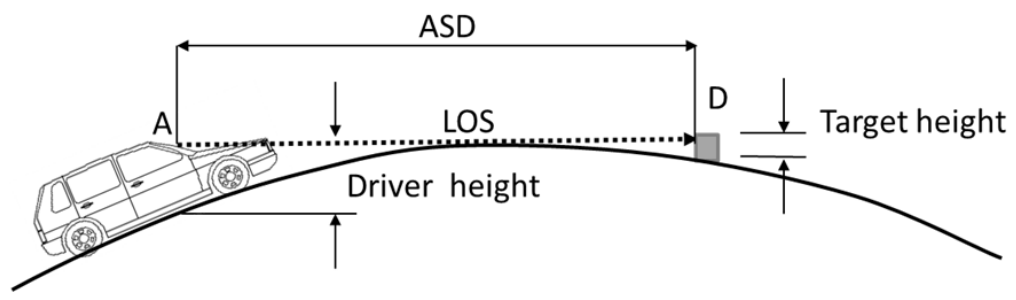

b) Profile view

Fig. 1. Available sight distance (ASD)

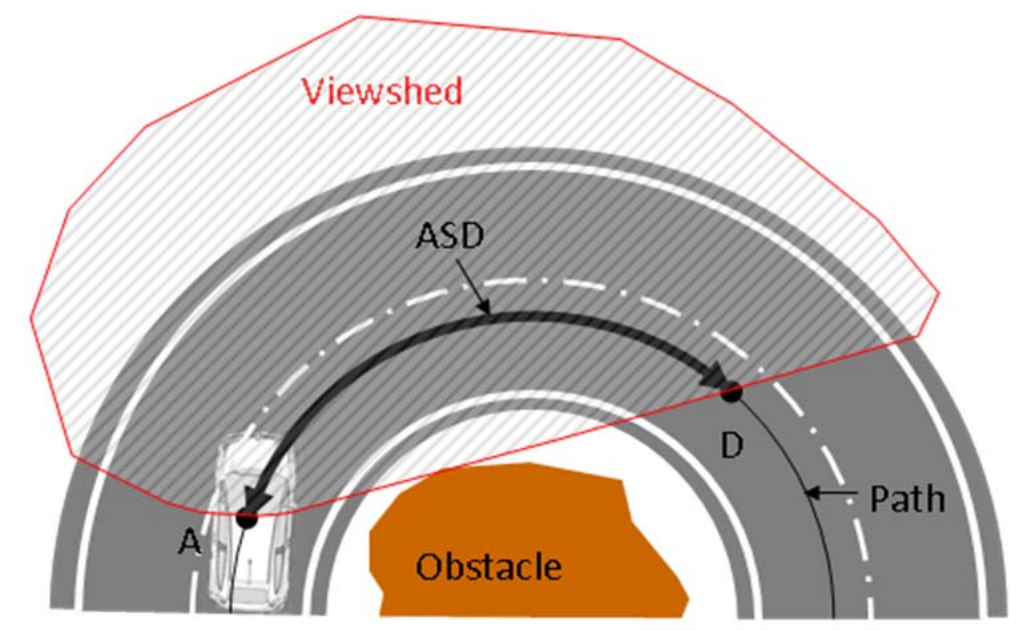

a)

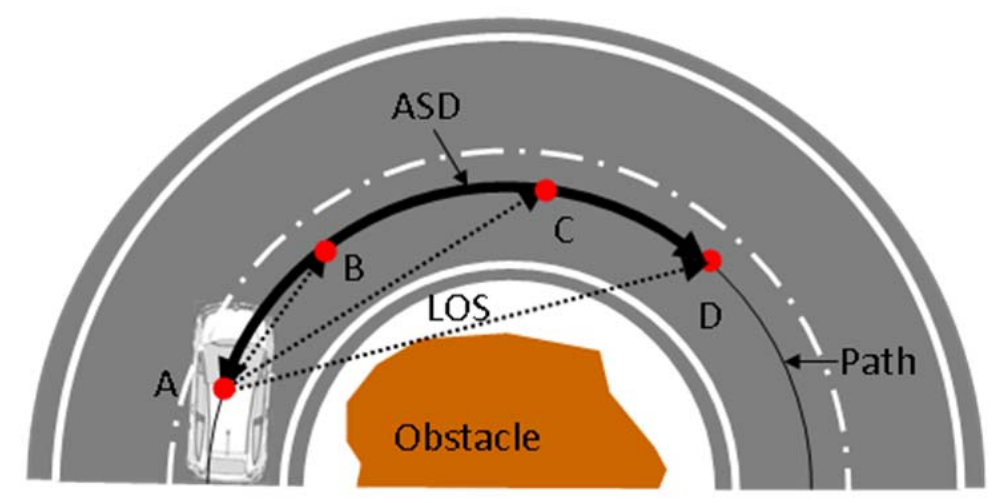

b)

Fig. 2. Available sight distance calculation using GIS. Possibilities 
in real time using the nearest base station.

Distance between calculation points is related with DTM. Five values of distance between points have been considered. Maximum value used is $20 \mathrm{~m}$, which is a frequent value used in Germany [10]. Minimum value is $1 \mathrm{~m}$ to obtain biggest detail that mesh step allows and it has been used only for DTM01. $1 \mathrm{~m}, 2 \mathrm{~m}, 5 \mathrm{~m}, 10 \mathrm{~m}$ and $20 \mathrm{~m}$ distance between points of the vehicle path have been used. The number of calculations of sight distance software depends on the distance between points of the path. For $1 \mathrm{~m}$ distance is, approximately, 14 million, and for $20 \mathrm{~m}, 0.03$ million (Table 1 ).

Tab. 1. Number of calculations

\begin{tabular}{cc}
\hline $\begin{array}{c}\text { Distance between } \\
\text { calculation points }(\mathbf{m})\end{array}$ & $\begin{array}{c}\text { Number of } \\
\text { calculations (million) }\end{array}$ \\
\hline 1 & 14 \\
\hline 2 & 3.50 \\
\hline 5 & 0.56 \\
\hline 10 & 0.14 \\
\hline 20 & 0.03 \\
\hline
\end{tabular}

Table 2 shows the twelve studied combinations of DTM resolution and distance between calculation points along the vehicle path. The $F 12$ case (corresponding to DTM01 and $1 \mathrm{~m}$ distance) has the highest terrain resolution and the lowest distance between path points among all cases. For these reasons, it has been chosen as reference case.

Tab. 2. Studied cases

\begin{tabular}{cccc}
\hline Designation & DTM & $\begin{array}{c}\text { Model } \\
\text { resolution }(\mathbf{m})\end{array}$ & $\begin{array}{c}\text { Distance between } \\
\text { calculation points (m) }\end{array}$ \\
\hline F12 & DTM01 & 1 & 1 \\
\hline F11 & DTM01 & 1 & 2 \\
\hline F10 & DTM01 & 1 & 5 \\
\hline F9 & DTM01 & 1 & 10 \\
\hline F8 & DTM01 & 1 & 20 \\
\hline F7 & DTM02 & 2 & 2 \\
\hline F6 & DTM02 & 2 & 5 \\
\hline F5 & DTM02 & 2 & 10 \\
\hline F4 & DTM02 & 2 & 20 \\
\hline F3 & DTM05 & 5 & 5 \\
\hline F2 & DTM05 & 5 & 10 \\
\hline F1 & DTM05 & 5 & 20 \\
\hline
\end{tabular}

In order to analyze visibility results, several comparisons of each case ( $F 1$ to $F 11$ ) against reference case $(F 12)$ have been made. First two performance indexes have been calculated and second a statistical analysis has been carried out.

Mean Absolute Error (MAE) and Root Mean Square Error (RMSE) have been chosen as performance indexes. Equations 1 and 2 show mathematical expressions of both indexes. $F i_{x}$ is sight distance in case $i$ (from 1 to 11 ) at point $X$ and $n$ is the number of points.

$$
\text { Mean Absolute Error } F i=\frac{\sum\left|F 12_{x}-F i_{x}\right|}{n}
$$

$$
\text { Root Mean Square Error } F i=\sqrt{\frac{\sum\left(F 12_{x}-F i_{x}\right)^{2}}{n}}
$$

To check if a case $(F i)$ and the reference case $(F 12)$ belong to the same distribution a Mann-Whitney W test and a KolmogorovSmirnov test have been made.

Available sight distance analysis is important because roads must have a minimum value of this one. For example, available sight distance has to be larger than the distance needed to stop a vehicle (stopping sight distance). In this sense, one study has been made to compare available sight distance calculated in the 12 cases and the stopping sight distance. Stopping sight distance depends on speed. $40 \mathrm{~km} / \mathrm{h}$ and $60 \mathrm{~km} / \mathrm{h}$ have been considered as speeds.

\section{Results and discussion}

\subsection{Performance indexes}

\subsubsection{Effect of DTM resolution}

In order to determine the DTM resolution effect, results of available sight distance obtained with the same distance between calculation points but different resolutions (DTM01, DTM02 and DTM05) were analyzed. Fig. 3 shows the results for $5 \mathrm{~m}$ distance between calculation points. In this figure, the $x$-axis is the distance, measured along vehicle path, between a calculation point and the beginning of the road section. Results of DTM 01 and 02 are similar, but significantly different than the DTM05 ones. The main differences correspond with slope changes in the graph (relative minima or maxima). DTM05 results are, generally, smaller than DTM01 and 02.

Mean absolute error $(M A E)$ calculated between every case ( $F 1$ to $F 11)$ and reference case $(F 12)$ is represented in Table 3 and Fig. 4. The Root Mean Square Error (RMSE) is shown in Table 4 and Fig. 5. Sight distance calculated with DTM05 shown high errors (i.e. hundreds of meters in Table 4). Therefore, it cannot consider the result obtained for mesh step of $5 \mathrm{~m}$ as reliable. DTM01 and DTM02 results are similar (except for the case of distance between calculation points $2 \mathrm{~m}$ ) with errors of tens of meters (MAE minor to $20 \mathrm{~m}$ and $R M S E$ minor to $40 \mathrm{~m}$ ). For a distance of $2 \mathrm{~m}$, the sight distance calculated with DTM01 presents a substantially smaller error than DTM02 (1 m vs $4.9 \mathrm{~m}$ ). In the case of DTM05, when distance between path points increases, results tend to improve (MRSE 180 for distance $5 \mathrm{~m}$ vs 162 for $20 \mathrm{~m}$, according Table 4 ).

Tab. 3. Mean absolute error (MAE) of sight distance

\begin{tabular}{ccccc}
\hline \multicolumn{5}{c}{ Distance between calculation points } \\
\hline DTM & $\mathbf{2 ~} \mathbf{~}$ & $\mathbf{5 ~} \mathbf{~}$ & $\mathbf{1 0} \mathbf{~}$ & $\mathbf{2 0 ~} \mathbf{~}$ \\
\hline DTM01 & 1.012 & 10.656 & 13.500 & 15.569 \\
\hline DTM02 & 4.905 & 10.403 & 10.094 & 15.506 \\
\hline DTM05 & - & 103.721 & 90.069 & 84.255 \\
\hline
\end{tabular}




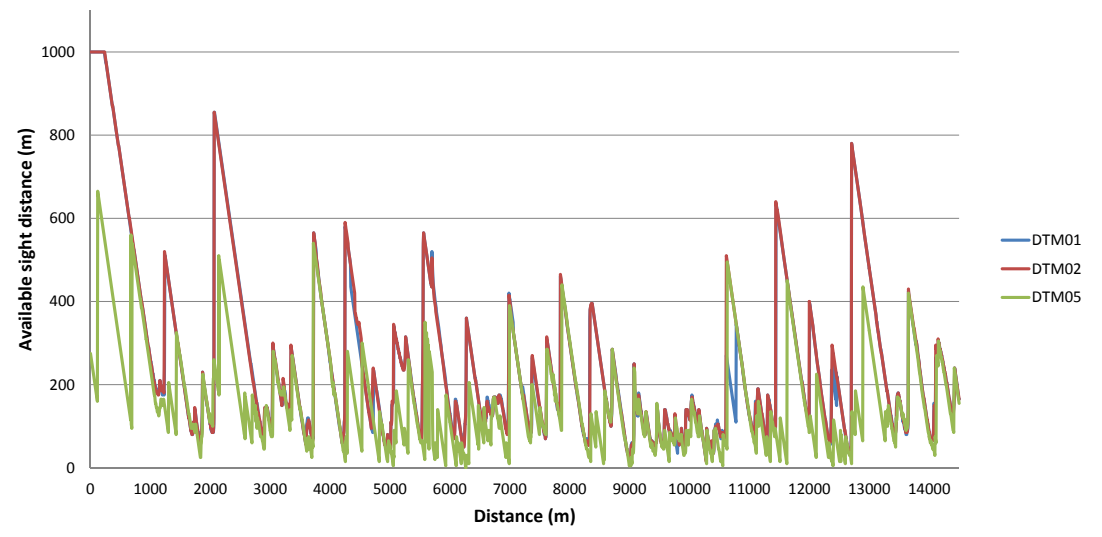

Fig. 3. Available sight distance for distance of 5 meters and DTM 01,02 and 05

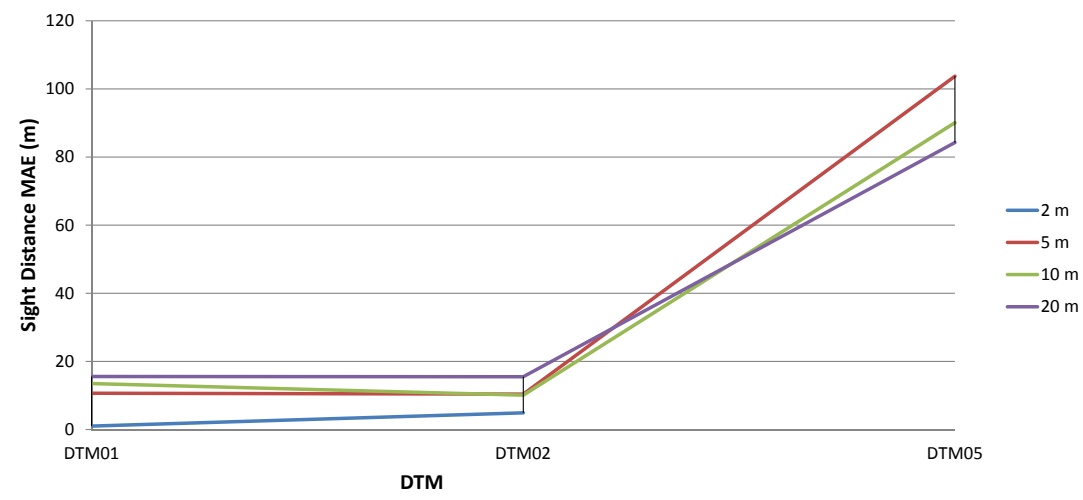

Fig. 4. DTM effect. Mean absolute error (MAE) of sight distance

Tab. 4. Root Mean Square Error (RMS E) of sight distance

\begin{tabular}{ccccc}
\hline \multicolumn{5}{c}{ Distance between calculation points } \\
\hline DTM & $\mathbf{2 ~} \mathbf{~}$ & $\mathbf{5 ~} \mathbf{~}$ & $\mathbf{1 0} \mathbf{~}$ & $\mathbf{2 0 ~} \mathbf{~}$ \\
\hline DTM01 & 7.114 & 43.153 & 48.567 & 44.434 \\
\hline DTM02 & 21.700 & 36.076 & 36.878 & 43.783 \\
\hline DTM05 & - & 188.831 & 174.728 & 162.836 \\
\hline
\end{tabular}

\subsubsection{Effect of distance between calculation points}

For each DTM, one figure comparing results for different distances between calculation points was obtained. Fig. 6 shows results calculated for DTM05. In this figure, the $x$-axis is the distance, measured along vehicle path, between a calculation point and the beginning of the road section. The main differences correspond with slope changes in the graph (relative minima or maxima). Generally, differences in the results due to the distance are lower than those due to the DTMs (Figs. 4 and 5 .

Tables 3 and 4 and Figs. 7 and 8 show the effect of distance between calculation points. For high resolution DTMs (DTM01 and 02), if distance between calculation points increases errors increase. When distance changes from 2 to $5 \mathrm{~m}$, e.g. for DTM 02 RMSE increase from 21.7 to $36 \mathrm{~m}$ (Table 4). By contrast, for the DTM 05, an increase in the distance between calculation points decreases errors in the sight distance (according to Table 4. MRSE is 180 for a distance of $5 \mathrm{~m}$ and 162 for $20 \mathrm{~m}$ ). Also, Figs. 7 and 8 clearly show that the effect of the DTM is greater than that of the distance (errors of tens of meters instead of hundreds of meters).

\subsection{Statistical analysis}

In order to study if a case and the reference case belong to the same distribution several tests has been made. First, the median of every case is compared in relation to reference case, through Mann-Whitney W Test (Table 5). This test is created combining both samples, ordering data from lowest to highest, comparing raking average of two samples in combined data. Making one hypothesis contrast in each case, it can be determined if there is statistically significant difference between case median with confidence level of $95 \%$. According W test there is no statistically significant difference between the median of sight distances calculated with DTM 01 or DTM02 with one confidence level of $95.0 \%$ for any distance between calculation points (p-value $>0.05$ in Table 5). However, there is statistically significant difference between the median of $F 12$ (i.e. DTM01 and distance between calculation points $1 \mathrm{~m}$ ) and the one calculated with DTM05 for any distance between calculation points (p-value $<0.05$ in Table 5).

In addition, Kolmogorov-Smirnov test has been made for every case in order to compare distribution between two samples (Table 6). This test is realized by calculating maximum distance between accumulated distributions of both samples. Making a 


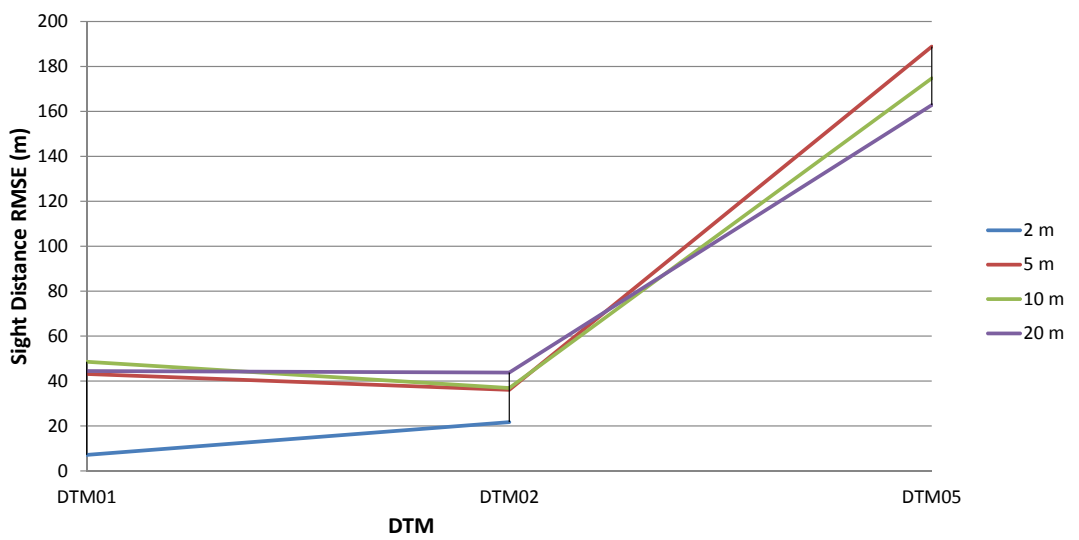

Fig. 5. DTM effect. Root Mean Square Error $(R M S E)$ of sight distance

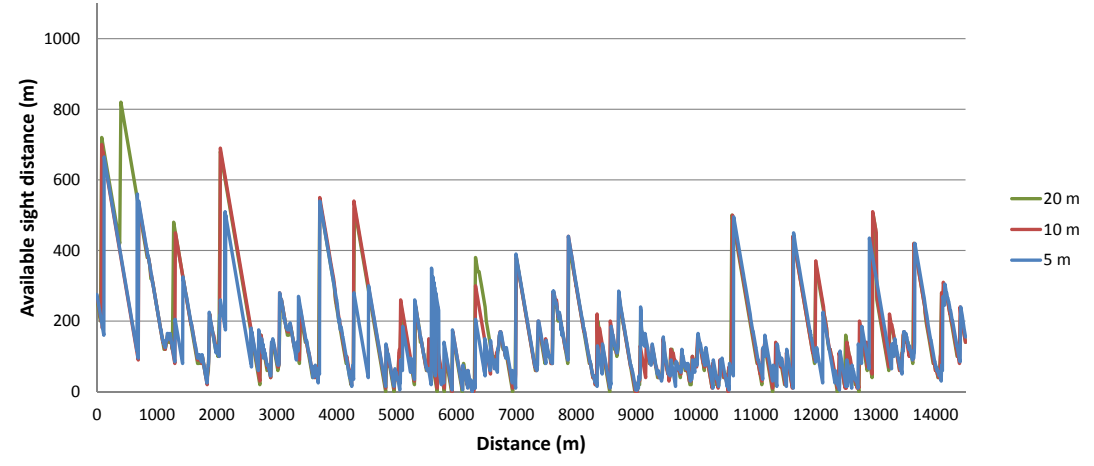

Fig. 6. Available sight distance for DTM05 and distance between points of 20,10 and $5 \mathrm{~m}$

Tab. 5. Mann-Whitney Test

\begin{tabular}{ccccc}
\hline DTM & \multicolumn{2}{c}{$\begin{array}{c}\text { Distance between } \\
\text { calculation points }(\mathbf{m})\end{array}$} & Count & \multicolumn{2}{c}{ Mann-Withney Test } \\
\cline { 2 - 5 } & 2 & 7251 & 52594450 & 0.9615 \\
\hline DTM01 & 5 & 2901 & 21288368 & 0.3025 \\
\cline { 2 - 5 } & 10 & 1451 & 10728365 & 0.2139 \\
\cline { 2 - 5 } & 20 & 726 & 5365306 & 0.3801 \\
\hline DTM02 & 2 & 7251 & 52321251 & 0.5636 \\
\cline { 2 - 5 } & 5 & 2901 & 21002901 & 0.9008 \\
\cline { 2 - 5 } & 10 & 1451 & 10580289 & 0.7206 \\
\hline DTM05 & 20 & 726 & 5353888 & 0.4361 \\
\cline { 2 - 5 } & 5 & & & \\
\cline { 2 - 5 } & 10 & 2901 & 27697348 & 0 \\
\cline { 2 - 5 } & 20 & 1451 & 13320996 & 0 \\
\hline
\end{tabular}

hypothesis contrast it can be shown if exists one statistically significant difference between both distributions with confidence level of 95\%. For DTMs with high resolution (DTM01 and DTM02) it is possible to conclude that there is no statistically significant difference between accumulated distributions with a confidence level of $95 \%$, respect reference case (F12), for any distance between path points ( $p$-value $>0.05$ in Table 6), except for $20 \mathrm{~m}$ distance ( $\mathrm{p}$-value $<0.05$ ). For DTM01, the distance $10 \mathrm{~m}$ is a case almost border ( $\mathrm{p}$-value $=0.055$ in Table 6). For DTM05 there is statistically significant difference between ac- cumulated distributions with one confidence level of $95.0 \%$ for any distance ( $\mathrm{p}$-value $<0.05$ in Table 6). This suggests that there is a minimum resolution for DTMs in order to calculate sight distances.

Tab. 6. Kolmogorv-Smirnov Test

\begin{tabular}{|c|c|c|c|c|}
\hline \multirow[t]{2}{*}{ DTM } & \multirow{2}{*}{$\begin{array}{l}\text { Distance between } \\
\text { calculation points }(\mathrm{m})\end{array}$} & \multirow[t]{2}{*}{ Count } & \multicolumn{2}{|c|}{ Kolmogorov-Smirnov Test } \\
\hline & & & Dn & P-Value \\
\hline \multirow[t]{4}{*}{$\overline{\text { DTM01 }}$} & 2 & 7251 & 0.0041 & 1.0000 \\
\hline & 5 & 2901 & 0.0173 & 0.4674 \\
\hline & 10 & 1451 & 0.0369 & 0.05466 \\
\hline & 20 & 726 & 0.063 & 0.00826 \\
\hline \multirow[t]{4}{*}{ DTM02 } & 2 & 7251 & 0.0092 & 0.8072 \\
\hline & 5 & 2901 & 0.0149 & 0.6545 \\
\hline & 10 & 1451 & 0.0313 & 0.1517 \\
\hline & 20 & 726 & 0.063 & 0.008257 \\
\hline \multicolumn{5}{|l|}{$\overline{\text { DTM05 }}$} \\
\hline & 5 & 2901 & 0.2185 & 0 \\
\hline & 10 & 1451 & 0.2055 & 0 \\
\hline & 20 & 726 & 0.2221 & 0 \\
\hline
\end{tabular}

It is not recommended using a DTM mesh step greater than 2 meters, since results obtained have an error too large (Table 6). For any DTM, using a distance of $20 \mathrm{~m}$ between calculation points is not recommended ( $\mathrm{p}$-value $<0.05$ ). 


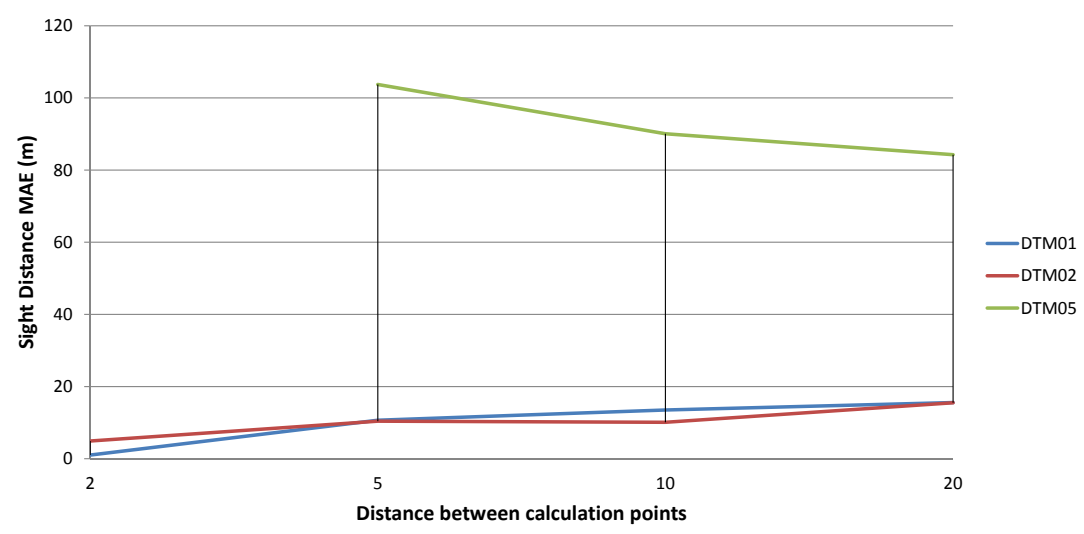

Fig. 7. Effect of distance between calculation points. Mean Absolute Error (MAE) of sight distance

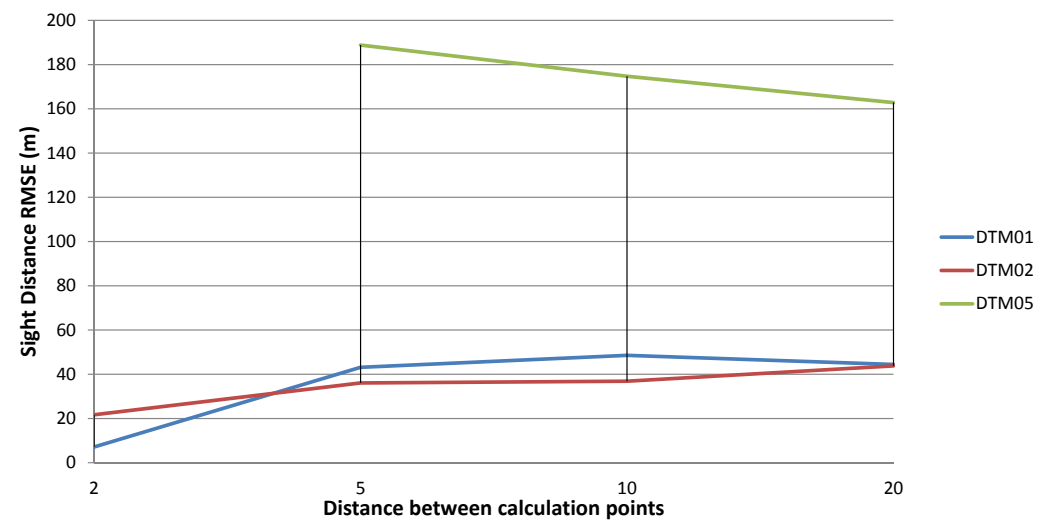

Fig. 8. Effect of distance between calculation points. Root Mean Square Error (RMSE) of sight distance

\subsection{Stopping sight distance}

For traffic safety, road design has to provide an available sight distance larger than the distance required to stop a vehicle (required stopping distance). Required stopping distance depends on speed. Given the road characteristics, a $40 \mathrm{~km} / \mathrm{h}$ design speed is assumed. For this speed, required stopping distance is $40 \mathrm{~m}$. Table 7 shows the cumulative section length whose available sight distance is lower than the required stopping distance $(40 \mathrm{~m})$. For to the case of DTM01 and distance between calculation points of $1 \mathrm{~m}$, the cumulative length with $\mathrm{ASD}<40 \mathrm{~m}$ is $151 \mathrm{~m}$ (these $151 \mathrm{~m}$ could be in one continuous section or in several non continuous sections). In the last column, the increase (in percentage), respect to reference case (DTM01 and distance between calculation points of $1 \mathrm{~m}$, i.e. $151 \mathrm{~m}$ ), is calculated.

In high resolution DTMs (DTM01 and DTM02), an increase in the distance between calculation points decreases the total length where available sight distance is lower than stopping distance. For the low resolution DTM (DTM05) results are unreliable, because the sum of section lengths where available sight distance is lower than required stopping distance, is more than $600 \%$ of reference case (Table 7).

According to Spanish standard [12], roads have a minimum sight distance, that corresponds with its design speed, and a desirable sight distance, that corresponds with its design speed incremented in $20 \mathrm{~km} / \mathrm{h}$. For this reason a new analysis is made
Tab. 7. Cumulative section length without stopping sight distance (for speed $=\mathbf{4 0} \mathbf{~ k m} / \mathbf{h}$ )

\begin{tabular}{|c|c|c|c|}
\hline DTM & $\begin{array}{c}\text { Distance between } \\
\text { calculation points }(\mathrm{m})\end{array}$ & $\begin{array}{c}\text { Cumulative length (m) } \\
\text { with } A S D<40 \mathrm{~m}\end{array}$ & $\Delta(\%)$ \\
\hline DTM01 & 1 & 151 & - \\
\hline DTM01 & 2 & 150 & -1 \\
\hline DTM01 & 5 & 110 & -27 \\
\hline DTM01 & 10 & 120 & -21 \\
\hline DTM01 & 20 & 120 & -21 \\
\hline DTM02 & 2 & 130 & -14 \\
\hline DTM02 & 5 & 125 & -17 \\
\hline DTM02 & 10 & 130 & -14 \\
\hline DTM02 & 20 & 120 & -21 \\
\hline DTM05 & 5 & 1170 & 675 \\
\hline DTM05 & 10 & 1070 & 609 \\
\hline DTM05 & 20 & 1120 & 642 \\
\hline
\end{tabular}

using a stopping sight distance $(80 \mathrm{~m})$ that corresponds to design speed plus $20 \mathrm{~km} / \mathrm{h}$ (i.e. $60 \mathrm{~km} / \mathrm{h}$ ). Table 8 shows the cumulative section length whose available sight distance is lower than the required stopping distance $(80 \mathrm{~m})$. In the last column, the increase (in percentage), respect to reference case (i.e. $1564 \mathrm{~m}$ ), is calculated. Although the numerical results are different in Tables 7 and 8 , the conclusions drawn are the same. 
Tab. 8. Cumulative section length without stopping sight distance (for speed $=60 \mathbf{~ k m} / \mathbf{h}$ )

\begin{tabular}{|c|c|c|c|}
\hline DTM & $\begin{array}{c}\text { Distance between } \\
\text { calculation points }(\mathrm{m})\end{array}$ & $\begin{array}{l}\text { Cumulative length (m) } \\
\text { with ASD }<40 \mathrm{~m}\end{array}$ & $\Delta(\%)$ \\
\hline DTM01 & 1 & 1564 & - \\
\hline DTM01 & 2 & 1544 & -1 \\
\hline DTM01 & 5 & 1510 & -3 \\
\hline DTM01 & 10 & 1510 & -3 \\
\hline DTM01 & 20 & 1500 & -4 \\
\hline DTM02 & 2 & 1534 & -2 \\
\hline DTM02 & 5 & 1470 & -6 \\
\hline DTM02 & 10 & 1500 & -4 \\
\hline DTM02 & 20 & 1460 & -7 \\
\hline DTM05 & 5 & 3845 & 146 \\
\hline DTM05 & 10 & 3410 & 118 \\
\hline DTM05 & 20 & 3320 & 112 \\
\hline
\end{tabular}

\section{Conclusions}

In this research twelve combinations of DTM resolution and distance between calculation points along the vehicle path have been studied. Each case study has been compared to a reference case which is considered close to reality. The analysis shows that DTM resolution has a larger effect on the results than distance between calculation points.

There is a minimum resolution for DTMs in order to calculate sight distances. If a coarser DTM is used, poor results are obtained. Using a DTM mesh step greater than 2 meters is not recommended since results obtained show an error too large. Distance between calculation points should be lower than $20 \mathrm{~m}$ and not lower than DTM mesh step. In choosing distance between points of the path, it should be taken into account that lower distance increases calculation effort and precision of results.

\section{Acknowledgements}

The Ministerio de Economía y Competitividad for their support in research project TRA2011-25479 (Convocatoria de 2011 de Proyectos de Investigación Fundamental no Orientada del Plan Nacional de I+D+i 2008-2011).

\section{References}

1 A Policy on Geometric Design of Highways and Streets, American Association of State Highway and Transportation Officials (AASHTO); Washington, DC, USA, 2004.

2 Berry R, Kidner D, The transition to high resolution digital surface models: Improvements in visibility analysis performance, GIS Research UK Annual Conference 2005, In: Proceedings of the GIS Research UK Annual Conference 2005, GIS Research UK Annual Conference 2005; Glasgow, UK, 2005, pp. 245-251.

3 Campoy-Ungría JM, Perez-Zuriaga AM, García A, CamachoTorregrosa FJ, Nueva metodología para obtención de visibilidades disponibles en carreteras a partir de datos LiDAR mobile, Rutas, 153, (2012), 16-23.

4 Castro M, Anta JA, Iglesias L, Sánchez JA, GIS-based system for sight distance analysis of highways, Journal of Computing in Civil Engineering, 28(3), (2014), 04014005-1-04014005-7, DOI 10.1061/(ASCE)CP.19435487.0000317
5 Castro M, Iglesias L, Sánchez JA, Ambrosio L, Sight distance analysis of highways using GIS tools, Transportation Research Part C: Emerging Technologies, 19(6), (2011), 997-1005, DOI 10.1016/j.trc.2011.05.012

6 Fisher P, Propagating effects of database generalization on the viewshed, Transactions in GIS, 1(2), (1996), 69-81, DOI $10.1111 / \mathrm{j} .1467-$ 9671.1996.tb00035.x

7 Hassan Y, Easa SM, EI Halim AOA, Analytical model for sight distance analysis on three-dimensional highway alignments, Transportation Research Record, 1523(1), (1996), 1-10, DOI 10.3141/1523-01

8 Jha MK, Karri GAK, Kuhn W, New three-dimensional highway design methodology for sight distance measurement, Transportation Research Record, 2262(1), (2011), 74-82, DOI 10.3141/2262-08

9 Kidner DB, Sparkes AJ, Dorey MI, Ware JM, Jones CB, Visibility analysis with the multiscale implicit TIN, Transactions in GIS, 5(1), (2001), 19-37, DOI 10.1111/1467-9671.00065

10 Kuhn W, Jha MK, Methodology for checking shortcomings in threedimensional alignment, Transportation Research Record, 2262(1), (2011), 13-21, DOI $10.3141 / 2262-02$

11 Lamm R, Psarianos B, Mailaender T, Highway design and traffic safety engineering handbook, McGraw-Hill; New York, 1999.

12 Norma 3.1-IC Trazado, Ministerio de Fomento; Madrid, Spain, 2000.

13 Murgoitio J, Shrestha R, Glenn N, Spaete L, Airborne LiDAR and terrestrial laser scanning derived vegetation obstruction factors for visibility models, Transactions in GIS, 18(1), (2014), 147-160, DOI 10.1111/tgis.12022

14 Ruiz MO, A causal analysis of error in viewsheds from USGS digital elevation models, Transactions in GIS, 2(1), (1997), 85-94, DOI 10.1111/j.14679671.1997.tb00007.x

15 Schuchmann G, Additions to and important remarks on the new Hungarian road design standard, Periodica Polytechnica Civil Engineering, 46(1), (2002), 3-15, http://www.pp.bme.hu/ci/article/view/616

16 Silyanov Vv, Comparison of the pattern of accident rates on roads of different countries, Traffic Engineering and Control, 14(9), (1973), 432-435.

17 Sparks WJ, The influence of highway characteristics on accident rates, Public Works, 99(3), (1968), 101-103.

18 Steenberghen T, Dufays T, Thomas I, Flahaut B, Intra-urban location and clustering of road accidents using GIS: a Belgian example, International Journal of Geographical Information Science, 18(2), (2004), 169-181, DOI 10.1080/13658810310001629619

19 GR-3 GNSS receiver specifications, Topcon Inc., 2007, http://wWw. topcon.co.jp/en/positioning/products/pdf/gr-3_e.pdf

20 Zimmermann M, Roos R, Increased safety resulting from quantitative evaluation of sight distances and visibility conditions of two-lane rural roads, 3rd International Symposium on Highway Geometric Design, In: Proceedings of the 3rd International Symposium on Highway Geometric Design, Transportation Research Board; Chicago, USA, 2005, pp. 1-14. 